El relato que a continuación se presenta, fue escrito como parte de un ejercicio metacognitivo dentro del primer módulo del Diplomado en Docencia y Gestión Curricular que ofrece el Centro de Estudios en Educación de la Universidad Santo Tomás de Bucaramanga, un programa orientado al desarrollo de competencias básicas de planificación, didáctica, evaluación y metacognición en el ejercicio docente.

Con la intención de favorecer la autorreflexión sobre los presaberes pedagógicos de los participantes y la forma en que se acercan o se distancian de la propuesta de la pedagogía problémica y del enfoque socioformativo de competencias, se les solicita que escriban la historia de su vida docente o su vida escolar. La premisa es que la historia de la educación se entreteje a partir de las historias personales que transcurren en las instituciones educativas y en las instituciones sociales en su conjunto.

El Ingeniero Jaime Díaz Ortiz nos permite asomarnos a una de esas historias- de ahí su riqueza- en la que encontramos un reconocimiento al rol que desempeñan las mujeres maestras en la educación escolarizada y en la formación para la vida que tiene lugar en la familia y en otros ámbitos de lo cotidiano; un reconocimiento que nos sirve de pretexto para agradecer a todos los maestros y maestras que han tocado nuestras vidas de manera permanente.

En el caso del relato que los lectores se disponen a disfrutar encontramos un sentido homenaje a la figura de la mujer maestra como pilar en la formación de ciudadanos íntegros e integrales. La riqueza de estos relatos estriba, en buena medida, en la posibilidad de asomarse a las historias que transcurren en las instituciones educativas en las que nos formamos porque es allí donde ocurre la historia de la educación. El Ingeniero Jaime Díaz Ortiz así lo ha entendido y nos ofrece su valioso aporte para la construcción de historias de vida educativas.

Brenda Isabel López Vargas Docente Diplomado en Docencia y Gestión Curricular CEE.

\title{
MI VIDA DOCENTE
}

Jaime Díaz Ortiz'

Mi experiencia en docencia y en la dirección de la academia es el resultado de las experiencias vividas desde cada etapa de mi formación.

Al iniciar mi desempeño docente tenía la tendencia de trasladar mis experiencias propias a los procesos académicos que lideraba. Esto incluía el modelo tradicional, magistral y casi que dictatorial. Los procesos de evaluación docente evidenciaron la necesidad de evolucionar a un modelo problémico, más humano y responsable.

Dada la coyuntura del día internacional de la mujer, he adelantado una retrospectiva de mi recorrido académico y docente y he encontrado que de manera significativa las mujeres han marcado el liderazgo en este proceso. El primer recuerdo es el de mi profesora Anita. Una mujer de origen antioqueño, morena, muy alta, creo que medía 1,58, pero desde la óptica de mis

1 Ingeniero Industrial de la Universidad Industrial de Santander. Magíster en Administración de Empresas de la Universidad Santo Tomás. Decano Académico de la Facultad de Ingeniería Industrial de esta Universidad.
4 años era casi inalcanzable. Ella me enseñó a leer y a conocer el reloj.

Poseedor de una fundamentación matemática basada en la habilidad de conocer el reloj y de obtener de él la información que a esa edad pocas personas potencializan, mi segundo recuerdo significativo proviene de quinto primaria con mi profesora Socorro Serrano. ¡Toda una Maestra!!! Ella me acompañó con una enseñanza personalizada y un enamoramiento y respeto por las normas, no solo gramaticales, sino orales y de disciplina. Hoy sigue viviendo en Zapatoca y en cada oportunidad la visito para llevarle mi afecto.. Mis hijos la reconocen como una persona que de manera especial tiene mi aprecio y respeto.

En secundaria mi profesora Ana Francisca Vargas de Ortiz me enseñó a pensar matemáticamente. Con ella no aprendí matemáticas. Aprendí a pensar matemáticamente, que es totalmente distinto. Aprendí a hacer cosas bien hechas en matemáticas, a interpretar mi entor- 
no y a conocerlo con base en la medición de cifras y en la comparación de cantidades, porcentajes y proporciones. Sin nosotros saberlo armaba situaciones problémicas a las que le daba solución manejando o induciendo nuestros gustos, hábitos y necesidades. Un día, antes del descanso, en un momento en el que los jóvenes de nuestra edad teníamos normalmente hambre y además por el clima de Barrancabermeja, una sed insostenible, la profesora Ana Francisca sacaba una manzana roja de su bolsa personal y decía que iba a repartir la manzana entre los seis integrantes del grupo de estudios. Lo mismo hacía con una jarra de limonada. Nos explicaba qué era un entero (una manzana completa), media manzana; un tercio de manzana, un cuarto de manzana; un quinto de manzana y el terrible un sexto de manzana, que implicaba la más pequeña de las porciones. Nunca olvidé los fraccionarios y las proporciones.

En décimo grado mi profesora Cristina Arenas de Bayona me enseñó la ortografía y redacción que ya creía saber y hoy le rindo el más sentido homenaje por su capacidad de liderar procesos en causas perdidas ya que como el ave Fénix, encendía la luz de la oscuridad en donde no había casi ninguna norma gramatical, obras que a nuestro nivel y con nuestras bases y presaberes hubieran sido un sueño imposible alcanzar. Al finalizar Once grado me revisó mi discurso de graduación y aunque le dio tres vueltas a mi borrador, ella insiste en que es mi obra. Digo que insiste porque aún, 25 años después de haberlo leído, hablamos al respecto.

Mi profesora Amparo Reyes me enseñó a pensar desde la óptica de las ciencias básicas como fundamento en ingeniería. Dedicó noches enteras a prepararme para presentar la prueba de ingreso a la UIS sin que yo tuviera cómo pagar esas horas de dedicación exclusiva a mi causa. Recia en sus pruebas escritas y orales e inamovible cuando de disciplina se trataba, pero con una mente despejada para fijar académicamente su vista en un futuro ingeniero.

En pregrado recuerdo a dos profesoras: Doña Amparo de Moreno y Myriam Leonor Niño.

Doña Amparo y Myriam, además de enseñarme organización y Métodos, Producción, Diseño de Plantas y Mercadeo, al igual que Administración de Sueldos y Salarios, por encima de cualquier información y conocimiento, me enseñaron a pensar desde el punto de vista de los procesos, de las permanentes mejoras, de no quedarme enfrascado en un problema, sino en la importancia de definir adecuadamente el problema y buscar varias alternativas de solución y a escoger la mejor.

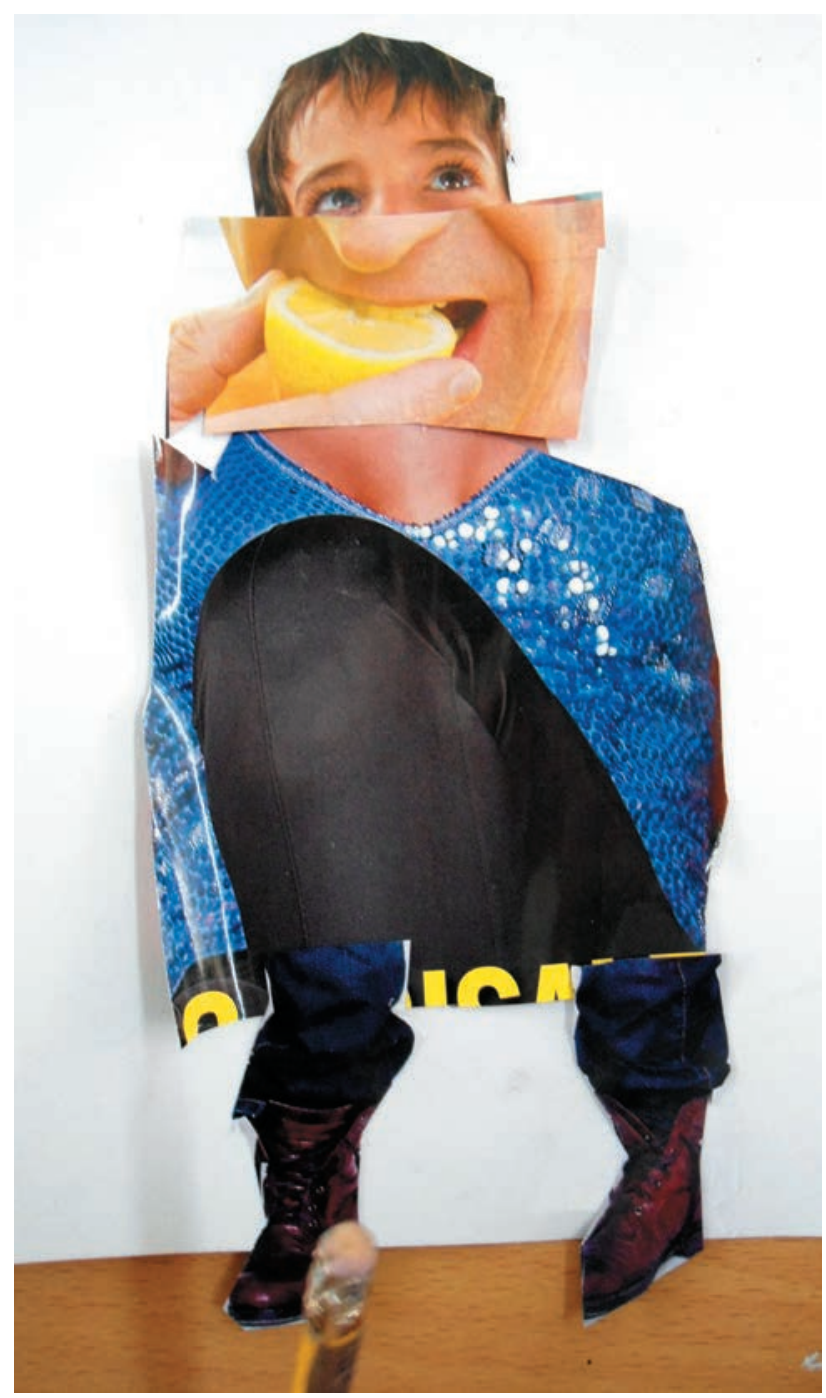

Imagen fotografía María Isabel Jasbón 


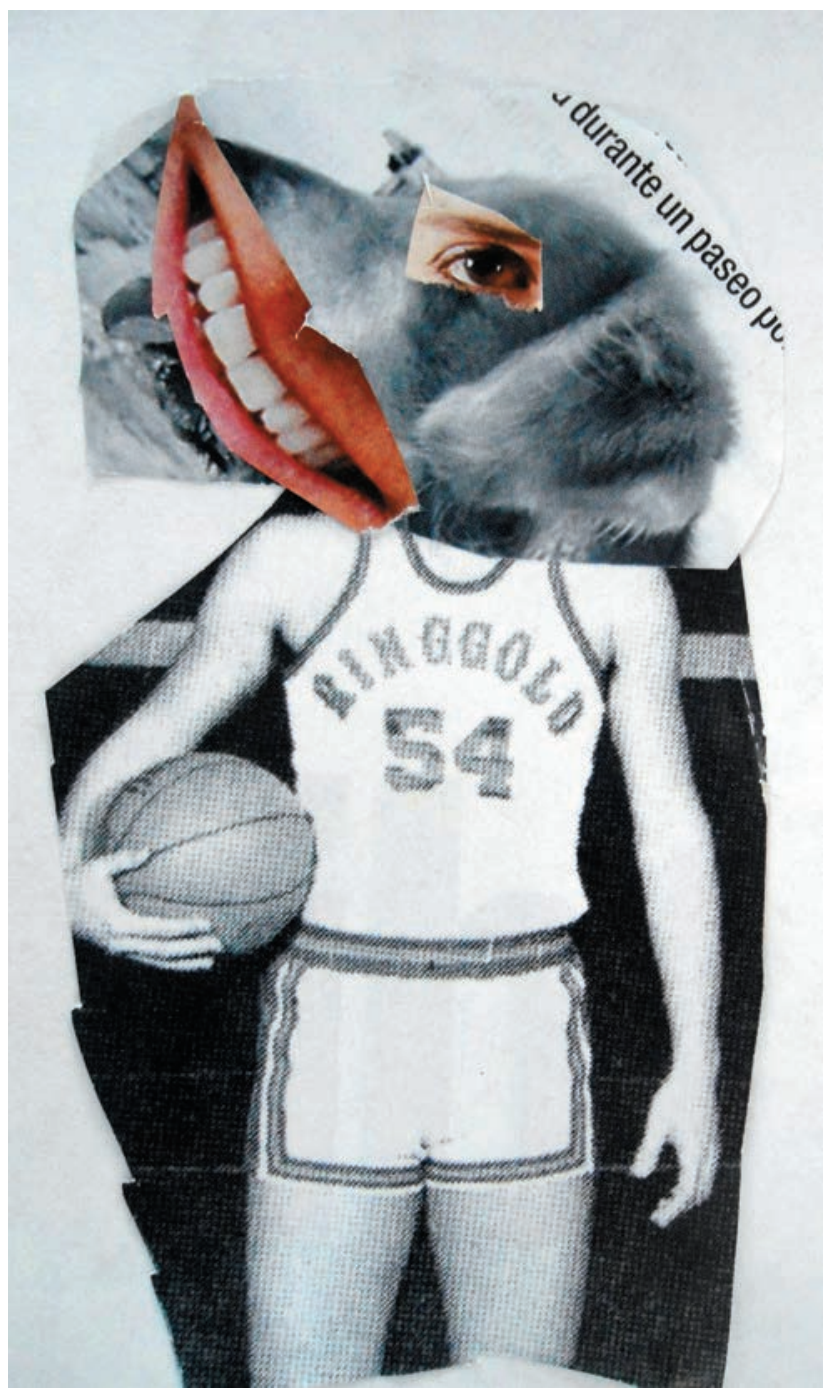

Imagen fotografía María Isabel Jasbón

En pregrado recuerdo a tres profesoras: María Josefa Domínguez Benítez (Pepita), Doña Amparo de Moreno y Myriam Leonor Niño.

En mi formación como Ingeniero Industrial tuve que esperar toda la carrera, hasta el último semestre, para poder conseguir un cupo en la asignatura de Arte y Sociedad, con Pepita, como se le conocía a la Profesora María Josefa Domínguez Benítez. Se exigía puntualidad, no ingresar a clase con gorra, no comer chicle y no fumar $-y$ todo ese dinero había que ahorrarlo para viajar. Pepita se paraba en la puerta y saludaba, de mano, a cada uno de los estudiantes por su nombre, de tal forma que a las dos semanas nos conocía a todos. La primera clase era un recorrido por el arte a lo largo de toda la historia de la humanidad, desde los tiempos de Stongenge hasta la actualidad: pintura, escultura y arquitectura. Por supuesto, era como si se nos hablara en arameo.

Cada clase, era dirigida por un artista personificado por cada uno de nosotros los estudiantes, donde contábamos "nuestra historia y nuestros aportes al arte", de tal forma que tuvimos la oportunidad de conversar en el aula, personalmente, con Leonardo, Rafael, Miguel Ángel, Miló, Renoir, y Vincent Van Gogh , entre otros, quienes nos contaron sus experiencias, sentimientos y emociones, al punto que los pudimos casi que entender. Ingenieros entendiendo a los artistas. El compromiso de la última clase fue esforzarnos durante nuestra vida por tener la oportunidad de conocer la Muralla China, las Pirámides de Egipto, la Acrópolis de Atenas, el Anfiteatro Flavio o Coliseo Romano, Notre Dame, y poder apreciar al David de Miguel Ángel, la Gioconda y casi que llorar con la Piedad. Debíamos recordar llevar agua y sombrilla para la extensa cola al ingresar a la Capilla Sixtina, si se visita en verano, y para recorrer la plaza de San Pedro y apreciar las losas de mármol traídas del otro lado del Mediterráneo, que el papa Julio Il le encargó a Miguel Ángel y luego a Rafael. Esa última clase era la misma primera clase, pero durante las 16 semanas habíamos aprendido arte y cultura de la humanidad: Cada uno de nosotros los estudiantes recitábamos los contenidos históricos y culturales de cada obra, con un perfecto dominio de "la lengua muerta" con la que, según nosotros, se nos impartió la primera clase. "Aprendimos arameo".

Y podría seguir detallando a cada una de estas docentes, pero las musas de las enseñanzas en mi vida están en mi casa: Mi abuela, mi madre y mi esposa. Sabias, recias como todas las santandereanas, mujeres de la casa y líderes de procesos. Ellas me enseñaron la disciplina, para ser ingeniero y mejorar como docente, me enseñaron amor por lo que se hace para querer $\mathrm{mi}$ profesión, me enseñaron a apreciar el resultado me los esfuerzos para sentir la satisfacción de 
ver el éxito de mis estudiantes, siempre aprendiendo de los problemas, del día a día y disfrutando el gusto por encontrar mejores soluciones a las dificultades.

El ser humano que ante todo debe ser todo docente, debe ser más sensible al entorno, para poder ser más pertinente a las necesidades de formación de los jóvenes que la sociedad nos asigna formar, en este caso, como profesiona- les. Por ello hoy la docencia es una profesión de la más alta responsabilidad social ya que por nuestras manos pasan los futuros líderes de una sociedad cada día más demandante en calidad de vida y por ello es clave que el mejoramiento en procesos productivos se puede aplicar en el mejoramiento del que-hacer docente, máximo para quienes creemos en que podemos construir una sociedad mejor. 